\title{
Arthroscopic meniscal repair evaluated by second-look arthroscopy*
}

\author{
CRAIG D. MORGAN, $†$ MD, EDWARD M. WOJTYS, $\ddagger \S M D$, \\ CHRISTOPHER D. CASSCELLS,§ MD, AND S. WARD CASSCELLS,§ MD
}

\author{
From the † Delaware Orthopedics Center, Wilmington, Delaware, and $\S$ MedSport, the \\ University of Michigan Department of Surgery, Ann Arbor, Michigan
}

\begin{abstract}
Of 353 arthroscopic peripheral meniscal repairs performed using the "outside to inside" suturing technique with rasp preparation of the tear region, 74 repairs $(50$ medial and 24 lateral) were assessed by second-look arthroscopy and are the basis of this report. Results were graded as either healed, incompletely healed, or failed; these findings were correlated with clinical symptoms and associated ACL deficiency. Overall, asymptomatic healing occurred in $84 \%$, with $65 \%$ healed and $19 \%$ incompletely healed. The failure rate was $16 \%$. All failures were symptomatic while all healed and incompletely healed menisci were asymptomatic. Failure was associated with ACL deficiency in all cases. No failures occurred in either an ACL uninjured knee or an ACL reconstructed knee. Failure was also associated with tear location in the posterior horn of the medial meniscus. Eleven of 12 failures $(92 \%)$ involved posterior medial meniscal tears with only 1 failure located posterolaterally. Visual evidence of healing required a 4 month time interval.
\end{abstract}

Meniscal tears are the most common intraarticular knee injury, comprising $75 \%$ or more of all internal derangements of the knee. ${ }^{47}$ Historically, operative treatment for symptomatic meniscal tears involved total meniscectomy by arthrotomy regardless of tear type, size, or location. This procedure, which was once felt to be benign, ${ }^{51}$ has subsequently been shown to produce grave long-term sequellae. Fairbank ${ }^{17}$ was the first to clinically demonstrate the deleterious longterm affects of total meniscectomy. His classic description of radiographic joint space narrowing, flattening of the fem-

\footnotetext{
*Presented at the 15th Annual Meeting of the AOSSM, Traverse City, Michigan, June 1989.

$\mp$ Address correspondence and reprint requests to: Edward M. Wojtys, MD. MedSport, P.O. Box 363, Ann Arbor, MI 48106-0363.
}

oral condyle, and marginal osteophyte formation after meniscectomy remains a landmark work documenting subsequent progressive hyaline cartilage failure. Jorgensen et al., ${ }^{31}$ in a long-term prospective study of 147 meniscectomies done for isolated meniscus tear, reported a $53 \%$ incidence of symptoms and a $40 \%$ incidence of Fairbanks changes at 4.5 years. By 14.5 years, $67 \%$ were symptomatic while $89 \%$ showed radiographic changes. These are not isolated or unusual findings. The literature is now replete with reports of both animal and clinical studies documenting mechanical alterations ${ }^{2,6,8,32,36,41,47,48}$ in the knee joint followed by clinical deterioration. $9,11,15,17,24,26-29,34,35,37,41,53$

Multiple attempts have been made to delineate meniscus function. Shrive ${ }^{49}$ in 1978 documented a spacer effect of the meniscus, which implied a load sharing function. Reports by Walker and coworkers ${ }^{54,55}$ using pressure transducers, and Ahmed, ${ }^{1}$ Fukubayashi, ${ }^{19}$ and Kurosawa ${ }^{33}$ using pressuresensitive film, concluded that the menisci transmit $50 \%$ to $60 \%$ of the load across an intact knee. Based on this knowledge and the development of arthroscopic techniques, open total meniscectomy gave way to partial meniscectomy in an attempt to preserve meniscus function in the remaining untorn portion of the meniscus. While direct comparisons have shown that partial meniscectomy clinically produced more favorable results than total removal, ${ }^{21,38,42,50,53}$ experimentally, partial removal still produced late articular cartilage changes. ${ }^{11}$

Scapinelli ${ }^{46}$ in 1968 and later Arnoczky ${ }^{3,4}$ in 1982 and 1983 found a peripheral meniscal blood supply limited to the outer one-quarter to one-third of the meniscus substance. This blood supply logically became the conceptual basis for potential healing of a peripheral meniscal repair. Since the meniscus cannot be removed either partially or totally without negative effects, and since partial meniscectomy in a patient with a radial tear essentially creates the effect of a total meniscectomy, peripheral meniscal repair has become an attractive alternative, particularly for the young. Early experience with meniscus repair was largely limited to open 
repair of medial meniscal detachments at the meniscocapsular junction. ${ }^{12-14,20,57}$ Due to difficulties with exposure and the position of the femoral condyle, vertical peripheral posterior horn tears located more than $2 \mathrm{~mm}$ central to the meniscocapsular junction are difficult if not impossible to approach by open arthrotomy. For this reason, arthroscopically assisted suturing techniques were developed and have improved the potential for repair of this injury. $7,10,16,22,39,44,56$

To date, published results of peripheral meniscal repair performed by either open or closed methods have been based largely on clinical parameters in relatively small series. ${ }^{7}, 10,12-14,16,20,22,23,39,43,44,56$ The purpose of this study was to assess a large series of arthroscopic peripheral meniscal repairs by delayed second-look arthroscopy to define the true incidence of healing and its relationship to clinical symptoms, and to identify risk factors associated with incomplete healing or failure. It was the authors' intention that the data obtained by repeat direct arthroscopic visualization would define an average time interval required for healing and form the basis of a new grading system for second-look results of peripheral meniscal suturing.

\section{MATERIALS AND METHODS}

The clinical material consisted of 353 outer third, displacable, single, vertical, and longitudinal meniscal tears greater than $1.5 \mathrm{~cm}$ in length repaired by a single arthroscopic technique. The technique consisted of tear debridement and local synovial abrasion with a rasp to stimulate a fibrous healing response, followed by absorbable suture stabilization of the torn region using the outside to inside method originally described by Warren ${ }^{56}$ and first reported clinically by Morgan and Casscells. ${ }^{39}$ Polydioxanone (O-PDS) (Ethicon, Somerville, NY) suture was used for all repairs.

As previously recommended by Morgan and Casscells, most knees (335) were immobilized postoperatively in full extension for 4 weeks and allowed immediate weightbearing. In 16 meniscal repairs ( 15 knees) combined with ACL reconstruction done by EMW, nonweightbearing with early motion was maintained for 6 weeks. In contrast, 35 knees, which had combined meniscal repair and ACL reconstruction done by CDM, CDC, and SWC, were immobilized in full extension for 4 weeks and allowed immediate weightbearing. At 1 week these patients were allowed active range of motion two times a day from $0^{\circ}$ to $60^{\circ}$ of flexion (while not walking) and were otherwise immobilized in full extension with full weightbearing when walking. In all knees, rigorous pivoting, sports contact, as well as full flexion exercises including squatting were not allowed for 6 months after surgery.

At the time of arthroscopic meniscal repair, records were kept regarding symptoms and their duration, meniscus tear location and length, and the status of the ACL as determined by examination under anesthesia and direct arthroscopic inspection. Associated ACL deficiency was found in 173 $(49 \%) ; 97(27 \%)$ of these were surgically stabilized by ar- throscopically assisted ACL reconstruction using bone-patellar tendon-bone or multiple thickness semitendinosus gracilis tendon autografts placed through isometric tibial and femoral drill holes either combined with meniscus repair in 51 or as a delayed procedure in 46 .

During a 6 year follow-up period, 74 repaired menisci or $21 \%$ of the larger clinical series were evaluated by repeat arthroscopy and form the basis of this report. The original repair involved the medial meniscus in 50 patients and the lateral meniscus in 24 patients. Ninety percent were posterior horn tears; with $10 \%$ extending into the midlateral or midmedial region from the posterior horn appearing as a peripheral bucket-handle tear pattern. Sixty-two percent of the second looks were in ACL deficient knees, $32 \%$ in ACL reconstructed knees, and 6\% in ACL uninjured knees. The average time between meniscal repair and repeat arthroscopy was 8.5 months, with a range from 2 months to 3 years. Average patient age was 26 years; 46 were men and 28 were women. Twenty-two repairs were done in recreational athletes, while 52 were done in competitive athletes.

Indications for a repeat arthroscopy were: one at the time of saphenous nerve exploration for neuroma, one at the time of semimembranosus ganglion excision, six at the time of arthroscopic resection of adhesions and manipulation under anesthesia for lack of full knee motion, 20 asymptomatic repairs in 10 consenting patients who had prior combined ACL reconstruction with biocompartmental posterior horn repairs and, 46 repairs at the time of delayed ACL reconstruction. In this ACL deficient group, there were 12 cases of meniscal repair failure that developed recurrent meniscal tear symptoms during the time between repair and delayed ACL reconstruction. All patients with clinical failure had a knee joint effusion, joint line tenderness and pain with full flexion on physical examination. These 12 cases represented all clinical failures $(3.4 \%)$ that occurred in the 353 original meniscus repairs, which therefore biased the second-look series toward failure (Table 1).

Meniscal repairs at repeat arthroscopy were graded as either healed, incompletely healed, or failed, according to the following criteria. A healed repair showed no defect or area of hypermobility to probing at the repair site and had no secondary tear in the meniscus in an area different from the repair site (Fig. 1). An incompletely healed repair had a

TABLE 1

Clinical results and second-look results vs. clinical symptoms

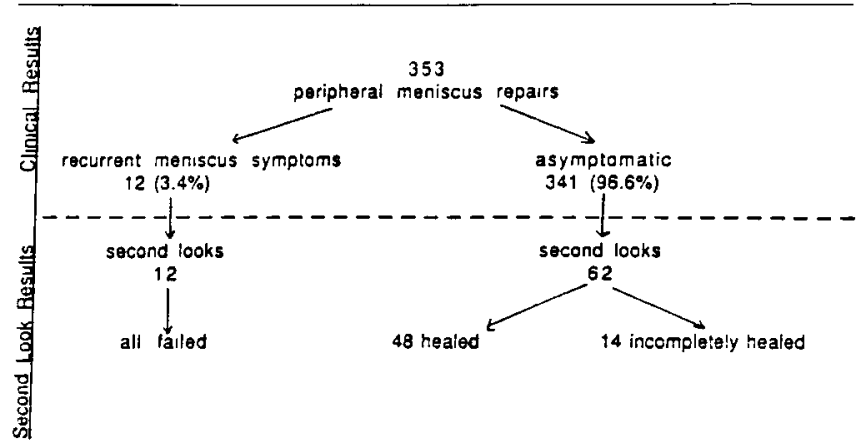




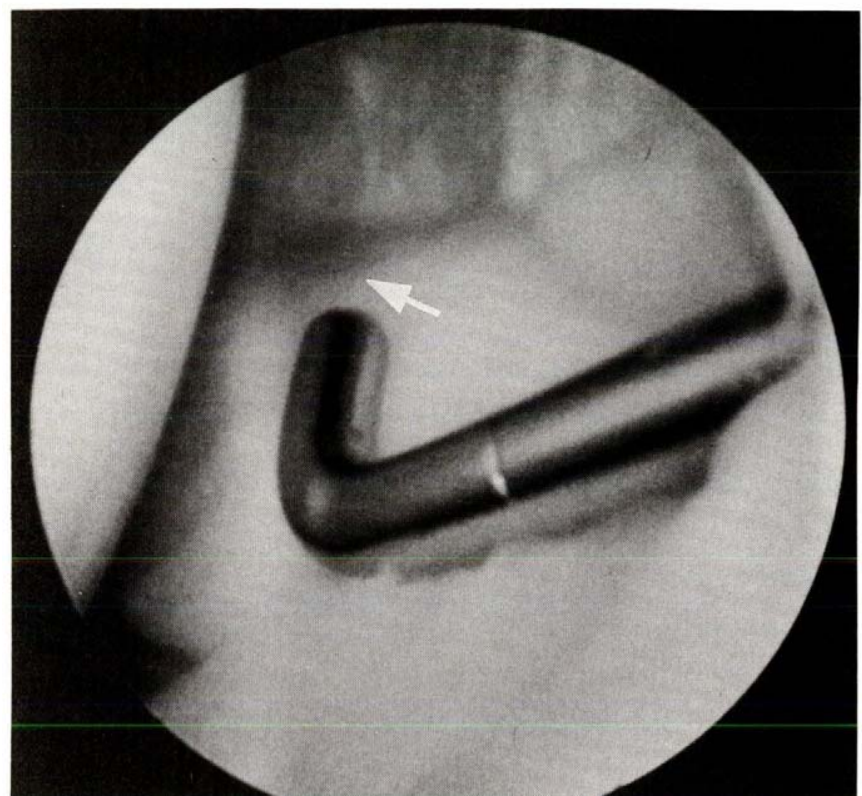

Figure 1. Healed medial meniscus 1 year after repair.

partial defect of less than $50 \%$ of the original repair length or height that was stable (not hypermobile) to probing and had no secondary tear in the meniscus in an area different from the repair site (Fig. 2). A failed repair had either a mobile (unstable) meniscus fragment secondary to rerupture at the original repair site or a second tear in the meniscal substance in an area different from the original repair site with a healed peripheral repair.

At second-look arthroscopy, details regarding the status of the ACL as either uninjured, reconstructed, or deficient were recorded and correlated with examination under anesthesia and meniscal findings. Also, clinical parameters indicative of meniscal retear including recurrent effusion, mechanical symptoms, localizing joint line tenderness, or a positive McMurray test were recorded and correlated with meniscal findings.

\section{RESULTS}

Results at second-look arthroscopy revealed an overall meniscal healing rate of $84 \%$ with $65 \%$ healed and $19 \%$ incompletely healed. The failure rate was $16 \%$ (12 cases), all of which were clinically symptomatic and detectable on preoperative physical examination. There were no second look proven false-negatives. In contrast, there were no falsepositives in the 62 asymptomatic second looks, of which 48 were healed and 14 incompletely healed. Based on this data, clinical parameters from the presecond-look history and physical examination were highly accurate in predicting meniscal failure after repair, but are of no value in predicting the incompletely healed but stable meniscal repair (Tables 1 and 2).
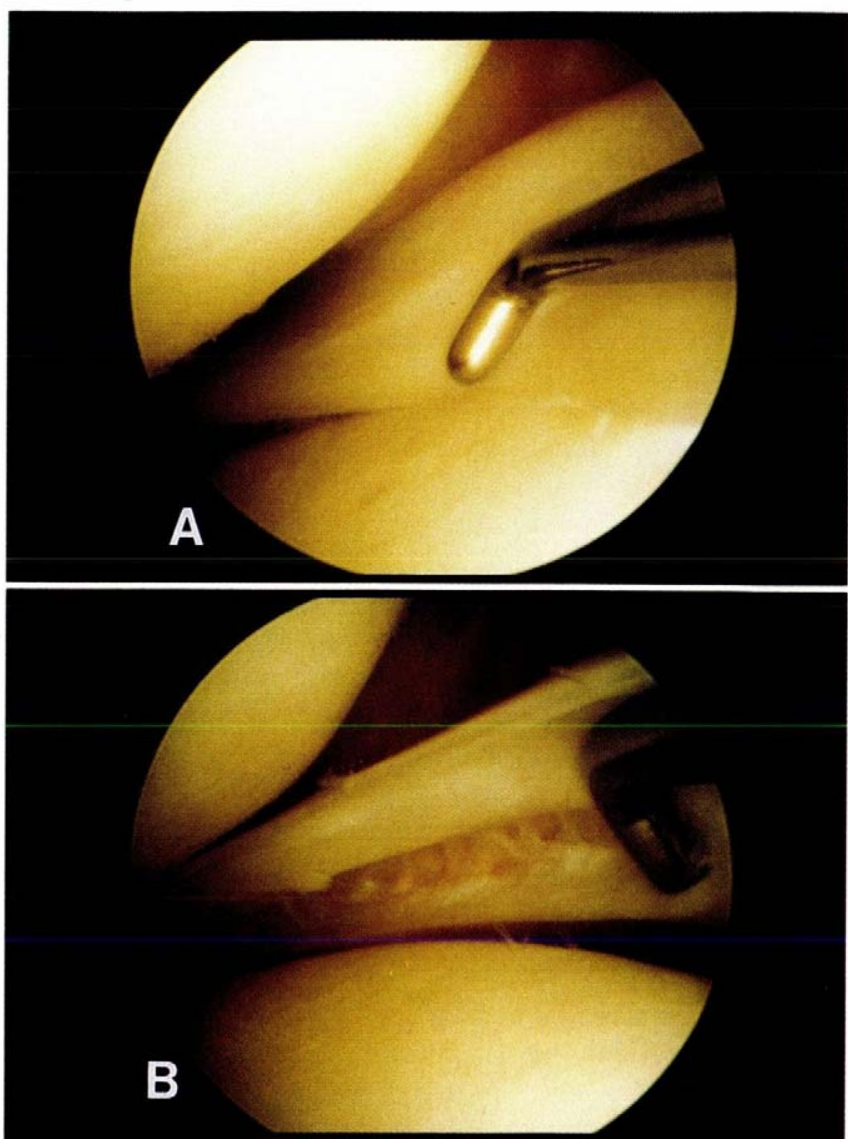

Figure 2. Incomplete healing of the medial meniscus. A, superior surface of the medial meniscus, no defect; $B$, inferior surface of the medial meniscus, defect present but nonhypermobile.

TABLE 2

Second-look results vs. repair location

\begin{tabular}{lclcc}
\hline \multicolumn{1}{c}{ Repair location } & $\begin{array}{c}\text { No. of } \\
\text { repairs }\end{array}$ & Healed & $\begin{array}{c}\text { Incompletely } \\
\text { healed }\end{array}$ & Failed \\
\hline Medial meniscus & 50 & 25 & 14 & 11 \\
Lateral meniscus & 24 & 23 & 0 & 1 \\
Total & 74 & $48(65 \%)$ & $14(19 \%)$ & $12(16 \%)$ \\
\hline
\end{tabular}

Meniscal repair failure was strongly associated with both ACL deficiency and original repair location in the posterior horn of the medial meniscus. Eleven of the 12 failures $(92 \%)$ were posteromedial repairs and all failures were associated with ACL deficiency in active, competitive athletes who opted for conservative treatment of their ACL tear rather than ACL reconstruction at the time of meniscal repair (Tables 2 and 3).

The ACL deficient knee with a posterior horn tear of the medial meniscus was found to be at highest risk for failure. Of 34 unstable, ACL deficient knees with a posteromedial meniscus repair, 11 or $32 \%$ were graded as failures at second look, as opposed to only 1 of 12 or $8 \%$ for unstable, ACL deficient posterolateral meniscal repairs. In contrast, no 
TABLE 3

Second-look results vs. ACL status

\begin{tabular}{lrccc}
\hline \multicolumn{1}{c}{ ACL status } & Total & Healed & $\begin{array}{c}\text { Incompletely } \\
\text { healed }\end{array}$ & Failed \\
\hline ACL deficient & 46 & $27(59 \%)$ & $7(15 \%)$ & $12(26 \%)$ \\
ACL reconstructed & 24 & $17(71 \%)$ & $7(29 \%)$ & 0 \\
ACL uninjured & 4 & $4(100 \%)$ & 0 & 0 \\
Total & 74 & $48(65 \%)$ & $14(19 \%)$ & $12(16 \%)$ \\
\hline
\end{tabular}

TABLE 4

Second-look results vs. ACL status and repair location

\begin{tabular}{lcccc}
\hline \multicolumn{1}{c}{ ACL status/site } & Total & Healed & $\begin{array}{c}\text { Incompletely } \\
\text { healed }\end{array}$ & Failed \\
\hline $\begin{array}{c}\text { ACL deficient, } \\
\text { medial }\end{array}$ & 34 & $16(47 \%)$ & $7(21 \%)$ & $11(32 \%)$ \\
$\begin{array}{c}\text { ACL deficient, } \\
\text { lateral }\end{array}$ & 12 & $11(92 \%)$ & 0 & $1(8 \%)$ \\
$\begin{array}{c}\text { ACL reconstructed, } \\
\text { medial }\end{array}$ & 16 & $9(56 \%)$ & $7(44 \%)$ & $0(0 \%)$ \\
$\begin{array}{c}\text { ACL reconstructed, } \\
\text { lateral }\end{array}$ & 8 & $8(100 \%)$ & $0(0 \%)$ & $0(0 \%)$ \\
$\begin{array}{c}\text { ACL uninjured, } \\
\text { medial }\end{array}$ & 0 & 0 & 0 & 0 \\
$\begin{array}{c}\text { ACL uninjured, } \\
\text { lateral }\end{array}$ & 4 & $4(100 \%)$ & 0 & 0 \\
\begin{tabular}{l} 
Total \\
\hline
\end{tabular} & 74 & $48(65 \%)$ & $14(19 \%)$ & $12(16 \%)$ \\
\hline
\end{tabular}

second-look failures occurred in the ACL uninjured (4) or the ACL reconstructed (24) meniscal repairs. Interestingly, the mode of failure in 4 of the 11 (36\%) medial failures was a flap tear at the posteromedial corner located central to the healed peripheral repair, while the other 7 medial meniscus failures and the 1 lateral meniscus failure were reruptures at the original peripheral repair site (Table 4).

Incomplete healing was also associated with posterior horn repair of the medial meniscus, particularly in the ACL deficient knee. All 14 incompletely healed menisci involved the posterior horn of the medial meniscus. Seven $(50 \%)$ were associated with ACL deficiency. The incompletely healed group tended to represent repairs assessed early in the healing process. Average time from repair to second look for the incompletely healed group was 4.7 months (range, 2 to 8 months). The average time from repair to second look for the entire group was 8.5 months (range, 2 months to 4 years). With this in mind, the incompletely healed repair may represent the early phase of healing, which may go on to a completely healed repair (Table 4). Conversely, the incompletely healed repair may, with repeat trauma, go on to fail at the deficient repair site.

In general, second-look findings revealed that a 3 to 4 month time period after repair was required for complete fibroblastic repair and disappearance of the previously placed absorbable suture material (Fig. 3).

\section{Complications}

In the original group of 353 arthroscopic meniscal repairs, there were 10 complications $(2.8 \%)$ that consisted of three deep infections that resolved with arthroscopic debridement, local wound care and antibiotics, four symptomatic adhesion

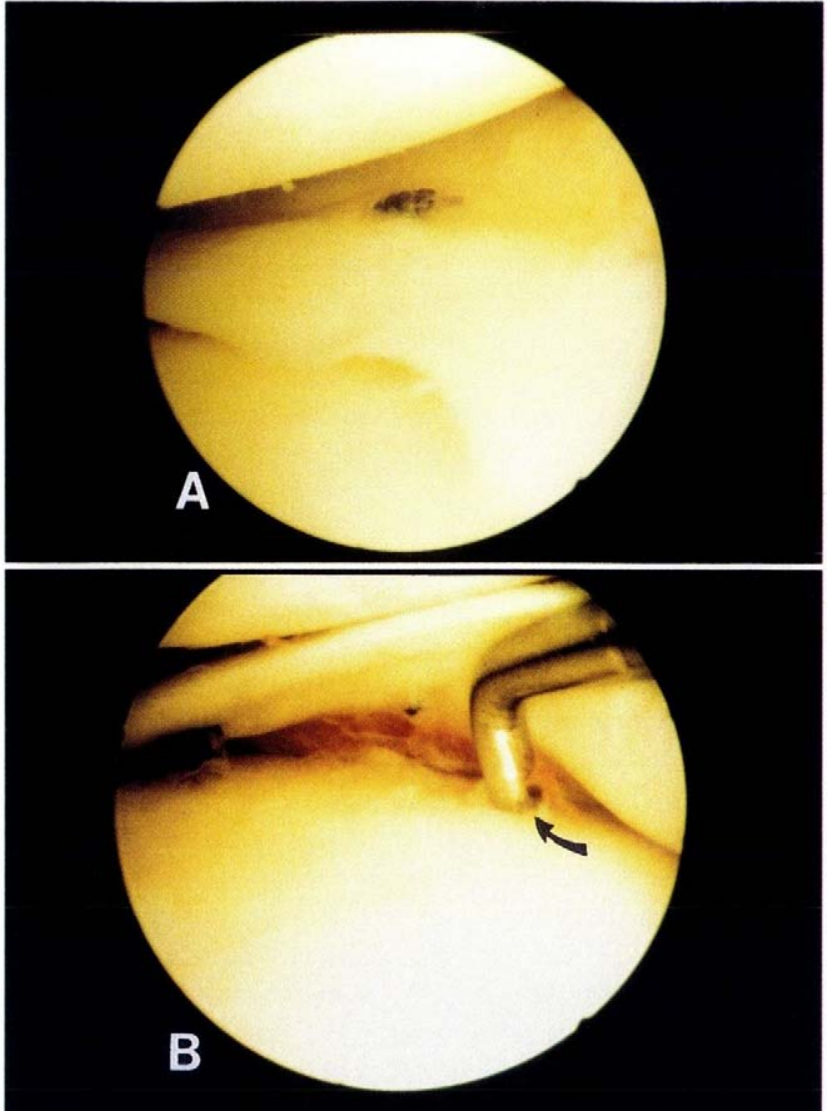

Figure 3. Early phase of healing, 3 months undissolved suture present. A, superior surface of the medial meniscus; B, inferior surface of the medial meniscus.

problems that required resection and manipulation under anesthesia, one nonfatal pulmonary embolus, four saphenous neuroma, and one semimembranosus ganglion. No complications occurred as a result of the 74 repeat arthroscopies.

\section{DISCUSSION}

The $16 \%$ failure rate in this study is clearly biased toward failure because the second-look group (74 repairs) included all clinically symptomatic patients from the larger group of 353 repairs. Although we recognize that it is invalid to equate lack of meniscus retear symptoms to healing in the larger clinical series (354) with a higher success rate, it is valid to note that all second look proven failures had clinical symptoms and signs of meniscal tear on physical examination. To the practicing clinician, the most important part of this report may be the fact that the clinical examination accurately predicted all failures in the second-look group with no false-positives.

Results of this study are similar to those of a smaller series of 29 second looks at arthroscopic meniscal repairs reported by Rosenberg ${ }^{44}$ in which the failure rate was $17 \%$. All of their failures involved the posterior horn of the medial 
meniscus with 4 of $5(80 \%)$ associated with ACL deficiency. In addition, no failures occurred in six of Rosenberg's ACL reconstructed knees. Hamberg ${ }^{20}$ reported 27 second looks of a larger series of open meniscal repairs in which 8 failures or $30 \%$ were identified, all involving the posterior horn of the medial meniscus in ACL deficient knees. DeHaven ${ }^{13}$ reported on 27 open meniscal repairs in ACL deficient knees and found a $29 \%$ meniscal repair failure rate associated with untreated ACL deficiency, but had only 1 failure $(7.6 \%)$ in 13 knees that had a combined ACL reconstruction and meniscus repair. Other authors including Jacob ${ }^{25} \mathrm{Ryu},{ }^{45}$ and Stone $^{52}$ have also identified ACL deficiency as a significant risk factor for meniscal repair failure.

Results of our study as well as others ${ }^{14,20,25,43,46,52}$ imply that the kinematics of the posterior horn of the medial meniscus in the ACL deficient knee are not conducive to meniscal healing after repair despite a peripheral blood supply. However, data from this study and others ${ }^{14,20,43}$ have shown that when combined with ACL reconstruction, peripheral meniscal repair healing rates improve and approach those obtained in the ACL uninjured knee. Several factors related to knee kinematics may be responsible for these findings. The menisci are part of the complex rotation mechanism of the intact knee. In that regard, they are intimately related during terminal extension to the screw home mechanism of the tibia. ${ }^{35,51}$ During terminal extension, the tibia externally rotates around a central vertical rotation axis of the femur. As part of this effect, we believe that the posterior horn of the medial meniscus, as well as the shape of the medial femoral condyle, are in part responsible for this rotation centered around the cruciate ligaments.

In the ACL deficient knee, this central vertical rotation axis is altered. It is this abnormal rotation axis near terminal extension in the ACL deficient knee that we postulate places excessive loads on the posterior horn of the medial meniscus due to both increased anterior tibial translation and increased external tibial rotation. Supporting this concept, Bach et al. ${ }^{5}$ reported a significant increase in the pivot shift phenomenon in ACL deficient knees when the test was performed with the tibia in external rotation. In addition, Jonsson et al., ${ }^{30}$ using roentgen stereophotogammetric methods, measured tibial movements in ACL deficient and intact knees at the time of the arthroscopy and reported reduced internal tibial rotation and adduction during terminal knee extension. During the last $30^{\circ}$ of extension, the ACL deficient knees in this study displayed anterior and distal displacements of the tibial intercondylar eminence when compared to intact knees.

Fu and coworkers ${ }^{18}$ have demonstrated that the posterior horn of the medial meniscus in an intact knee has a smaller anterior-posterior excursion range on the posterior tibial plateau than the posterior horn of the lateral meniscus during flexion and extension. This reduced mobility is caused by a more rigid attachment of the posteromedial horn to the tibia at the meniscotibial portion of the coronary ligament complex. In the ACL deficient knee, which may have excessive external tibial rotation and anterior tibial translation near terminal extension, we believe the posterior horn of the medial meniscus is more likely to fail because its attachment is more rigid and therefore cannot escape the medial femoral condyle as the tibia translates anteriorly and externally rotates in reference to the femur. Further supporting this concept, Shoemaker and Markoff ${ }^{48}$ demonstrated that the most effective portion of the medial meniscus in reducing anterior tibial translational forces was the posterior horn. During their testing procedure, they showed that partial posterior medial meniscus tears progressed to full thickness tears when subjected to anterior translational forces applied to the tibia.

Improved healing rates for posteromedial peripheral meniscal repairs, when combined with ACL reconstruction found in this and other studies, ${ }^{14,43}$ may be due to restoration of more normal anterior translation and external rotation characteristics between the femur and tibia. This important factor deserves further study. Also, it is interesting to speculate that ACL reconstruction and meniscal repair produces a much larger hemarthrosis than meniscal repair alone. This may play a role in the formation of a larger intraarticular clot at the meniscal repair site, which in turn may facilitate fibroblastic repair. A third possibility includes the prolonged rehabilitation program that is encountered with ACL reconstruction.

It has been the first author's clinical experience while viewing peripheral posterior horn tears with a $70^{\circ}$ scope through the intercondylar notch that knee flexion causes posterior horn tears to separate from the capsule and terminal extension of the knee reduces these tears regardless of the ACL status. For this reason, we recommend tying the meniscus repair sutures and immobilizing the knee in full extension whenever possible as originally reported in $1986 .{ }^{39}$

\section{CONCLUSIONS}

Clinical parameters in the history and physical examination indicative of meniscal retear were accurate in predicting second look proven meniscal repair failure in all 12 cases. In this series of 74 second looks, the overall asymptomatic healing rate was $84 \%$, with $65 \%$ healed and $19 \%$ incompletely healed but stable to probing. Initial visual signs of healing after repair required a 4 month time interval. The failure rate was $16 \%$. Failure was associated with meniscal tear location in the posterior horn of the medial meniscus and ACL deficiency.

\section{REFERENCES}

1. Ahmed AM, Burke DL, Zsombor-Murray PJ: Design aspects of an apparatus from the static loading of two-component synovial joints. Paper from the Dept. of Mechanical Engineering, McGill University, Montreal, Canada

2. Allen PR, Denham RA, Swan AV: Late degenerative changes after meniscectomy. J Bone Joint Surg 66B: 666-671, 1984

3. Arnoczky SP, Warren RF: The microvasculature of the meniscus and its response to injury: An experimental study in the dog. Am J Sports Med 11: 131-141, 1983

4. Arnoczky SP, Warren RF: Microvasculature of the human meniscus. Am J Sports Med 10: 90-95, 1982

5. Bach BR, Warren RF, Wickiewicz TL: The pivot shift phenomenon: Results 
and descriptions of a modified clinical test for anterior cruciate ligament insufficiency. Am J Sports Med 16: 571-576, 1988

6. Baratz ME, Fu FH, Mengatyo R: Meniscal tears: The effect of meniscectomy and of repair on intraarticular contact areas and stress in the human knee. Am J Sports Med 14: 270-275, 1986

7. Barber FA, Stone RG: Meniscus repair-An arthroscopic technique. $J$ Bone Joint Surg 678: 39-41, 1985

8. Bourne RB, Finlay JB, Papadopoulos P, et al: The effect of medial meniscectomy of strain distribution in the proximal part of the tibia. J Bone Joint Surg 66A: 1431-1437, 1984

9. Burman MS, Sutro CJ: A study of the degenerative changes of the menisci of the knee joint and the clinical significance thereof. J Bone Joint Surg 15: 835-861, 1933

10. Clancy WG, Graf BK: Arthroscopic meniscus repair. Orthopaedics 6: 11251129,1983

11. Cox JS, Nye CE, Schaefer WW, et al: The degenerative effects of the partial and total resection of the medial meniscus in dogs' knees. Clin Orthop 109: 178-183, 1975

12. DeHaven KE: Meniscus repair in the athlete. Clin Orthop 198: 31-35, 1985

13. DeHaven KE: Meniscus repair-open vs. arthroscopic. Arthroscopy 1 : $173-174,1985$

14. DeHaven KE: Peripheral meniscus repair: An alternative to meniscectomy. $J$ Bone Joint Surg 63B: 463, 1981

15. DiStefano, VJ: Function: Post-traumatic sequelae and current concepts of management of knee meniscus injuries: A review article. Clin Orthop 151: $143-146,1980$

16. DiStefano VJ, Bizzle P: A technique of arthroscopic meniscoplasty. Orthopaedics 6: $1135-1139,1983$

17. Fairbank TJ: Knee joint changes after meniscectomy. $J$ Bone Joint Surg 30B: $664-670,1948$

18. Fu FH, Thompson WO, Thaete FL, et al: Tibial meniscal dynamics using 3D reconstruction of MR images. American Orthopaedic Society for Sports Medicine 15th Annual Meeting, Traverse City, Michigan, June 19-22, 1989

19. Fukubayashi $Y$, Kurosawa $H$ : The contact area and pressure distribution pattern of the knee. Acta Orthop Scand 51: 871-879, 1980

20. Hamberg $P$, Gillquist, $J$, Lysholm J: Suture of new and old peripheral meniscus tears. J Bone Joint Surg 65A: 193-197, 1983

21. Hede A, Hejgaard N, Larsen E: Partial or total open meniscectomy? A prospective, randomized study. Int Orthop 10: 105-108, 1986

22. Henning CE: Arthroscopic repair of meniscus tears. Orthopaedics 6: 11301132,1983

23. Henning CE, Lynch MA, Clark JR: Vascularity for healing of the meniscus. Arthroscopy 3: 13-18, 1987

24. Huckell JR: Is meniscectomy a benign procedure? A long-term follow-up study. Can J Surg 8: 254-260, 1965

25. Jacob RP, Staubli HU, Zuber K, et al: The arthroscopic meniscal repair: Techniques and clinical experience. Am J Sports Med 16: 137-142, 1988

26. Jackson JP: Degenerative changes in the knee after meniscectomy. $\mathrm{Br}$ Med J 2: 525-527, 1968

27. Johnson RJ, Kettlekamp DB, Clark W, et al: Factors affecting late results after meniscectomy. $J$ Bone Joint Surg 56A: 719-729, 1974

28. Johnson RJ, Pope MH: Functional anatomy of the meniscus. American Academy of Orthopaedic Surgeons. Symposium on Reconstructive Surgery of the Knee, St. Louis, C.V. Mosby, Co., 1978, pp 3-13

29. Jones RE, Smith EC, Reisch JS: Effects of medial meniscectomy in patients older than forty years. $J$ Bone Joint Surg 60A: 783-786, 1978

30. Jonsson H, Karrholm J, Elmqvist LG: Kinematics of active knee extension after tear of the anterior cruciate ligament. Am J Sports Med 17: 796-802, 1989

31. Jorgensen U, Sonne-Holm S, Lauridsen F, et al: Long-term follow-up of meniscectomy athletes. J Bone Joint Surg 69: 80-83, 1987

32. Krause WR, Pope MH, Johnson RJ, et al: Mechanical changes in the knee after meniscectomy. J Bone Joint Surg 58A: 599-604, 1976

33. Kurosawa $\mathrm{H}$, Fukubayashi $\mathrm{T}$, Nakajima $\mathrm{H}$ : Load bearing mode of the knee joint: Physical behavior of the knee joint with or without menisci. Clin Orthop 149: 283-290, 1980

34. Laasonen EM, Wilppula E: Why a meniscectomy fails. Acta Orthop Scand 47: 672-675, 1976

35. Lagergren KA: Meniscus operations and secondary arthrosis deformans. Acta Orthop Scand 14: 280-287, 1953

36. Levy IM, Torzilli PA, Warren RF: The effect of medial meniscectomy on anterior/posterior motion of the knee. J Bone Joint Surg 64A: 883-888, 1982

37. Luft AM: Morphological changes in the articular cartilage after meniscectomy. J Bone Joint Surg 57B: 525-528, 1975

38. McGinty JB, Geuss LF, Marvin RA: Partial or total meniscectomy. J Bone Joint Surg 59A: 763-766, 1977

39. Morgan CD, Casscells SW: Arthroscopic meniscus repair: A safe approach to the posterior horns. Arthroscopy 2: 3-12, 1986
40. Moskowitz RW, Davie W, Sammarico J, et al: Experimentally induced degenerative joint lesions following partial meniscectomy in the rabbit. Arthritis Rheum 16: 197-405, 1973

41. Oretorp N, Alm A, Ekstrom H, et al: Immediate effects of meniscectomy on the knee joint: The effects of tensile load on knee joint ligaments in dogs. Acta Orthop Scand 49: 407-414, 1987

42. Radin EL, LaMotte F, Maquet P: Role of the menisci in the distribution of stress in the knee. Clin Orthop 185: 290-294, 1984

43. Rosenberg TD, Scott SM, Coward DB, et al: Arthroscopic meniscal repair evaluated with repeat arthroscopy. Arthroscopy 2: 14-20, 1986

44. Rosenberg T, Scott S, Paulos L: Arthroscopic surgery: Repair of peripheral detachment of the meniscus. Contemp Orthop 10: 43-50, 1984

45. Ryu RKN, Dunbar WH: Arthroscopic meniscai repair with two year followup: A clinical review. Arthroscopy 4: 168-173, 1988

46. Scapinelli R: Studies on the vasculature of the human knee joint. Acta Anat 70: 305-331, 1968

47. Shands AR, Hutchinson JL, Ziv L: Derangements of the semilunar cartilages of the knee: A clinical and experimental study. South Med $J 29$ : 1045-1050, 1936

48. Shoemaker SC, Markholf KL: The role of the meniscus in the anterior/ posterior stability of the loaded anterior cruciate-deficient knee. J Bone Joint Surg 68A: 71-79, 1986

49. Shrive NG, O'Connor JJ, Goodfellow JW: Load bearing in the knee joint. Clin Orthop 131: 279-287, 1978

50. Simpson DA, Thomas NP, Aichroth PM: Open and closed meniscectomy. $J$ Bone Joint Surg 68B: 301-304, 1986

51. Smillie JS: Injuries to the knee joint. Baltimore, Williams \& Wilkins, 1961

52. Stone RG, VanWinkle GN: Arthroscopic review of meniscal repair assessment of healing parameters. Arthroscopy 2: 77-81, 1986

53. Tappen EM, Hoover NW: Late results after meniscectomy. $J$ Bone Joint Surg 51A: 517-526, 1969

54. Walker PS, Hajek JV: Load bearing area in the knee joint. J Biomech 5: $581-589,1972$

55. Walker PS, Erkman MJ: The role of the menisci in force transmission across the knee. Clin Orthop 109: 184-192, 1975

56. Warren RF: Arthroscopic meniscus repair. Arthroscopy 1: 170-172, 1985

57. Wirth CR: Meniscus repair. Clin Orthop 157: 153-160, 1981

\section{COMMENTARY}

W. Dilworth Cannon, Jr., MD, San Francisco, California: The authors report a projected meniscal healing rate of $96.6 \%$, an extremely high figure. However, they have repaired only vertical longitudinal tears in the outer one-third of vascularized area of the meniscus, an area that one would expect to achieve good results.

My main criticism of this paper is that they have projected the results from a small group of 74 second looks onto the entire series of 353 patients. This an assumption that has not been confirmed by other authors. Of the 74 second looks, there were only 4 isolated menisci repairs with intact ante. rior cruciate ligaments which all healed, whereas in their larger series there were 180 isolated meniscal repairs for which they had projected a $100 \%$ healing rate.

In both Hennings' and my series of isolated repairs, before the use of fibrin clot and using similar criteria for healing, only $60 \%$ were healed. The authors also state that anatomical failures correlated precisely with clinical failures. This differs from Henning, who found that two-thirds of his anatomical failures were clinical successes. In my own series, $47 \%$ of the anatomical failures were also clinically healed.

I would suggest that in reporting the results of meniscal repair that anatomical results be reported separately from clinical results. Clinical results that are not based on secondlook arthroscopy will always seemingly produce better results. The authors found that all 14 of their incompletely 
healed menisci involved the posterial horn of the medial meniscus. However, Henning and I have found a significant number of incompletely healed menisci to involve a lateral meniscus and tears around the popliteal hiatus, a notoriously poorly vascularized area of the bilateral meniscus.

The authors had a $26 \%$ failure rate in ACL deficient knees that were not reconstructed somewhat to DeHaven's $38 \%$ in the group that were followed for a longer period of time.
They brought 46 repairs back for delayed ACL reconstruction. I would hope that in the future more patients will undergo simultaneous meniscal repair and ACL reconstruction. Aside from these criticisms, the authors have presented excellent results in the large group of meniscal repairs. Hopefully this will further reinforce the concept of meniscal repair rather than excision, especially in an ACL deficient knee. 